\title{
PENGARUH STRES SITUASI KERJA TERHADAP PSYCHOLOGICAL WELL-BEING PADA GURU HONORER MADRASAH IBTIDAIYAH DI KOTA TANGERANG
}

\author{
${ }^{1}$ Fitri Lestari Issom \& ${ }^{2}$ Raisata Makbulah \\ e-mail: fitrilestari@gmail.com \\ Fakultas Pendidikan Psikologi Universitas Negeri Jakarta
}

Jalan Halimun Raya No.2 Jakarta Selatan

\begin{abstract}
Abstrak: Penelitian ini bertujuan untuk mengetahui pengaruh stres situasi kerja terhadap psychological well-being. Populasi dalam penelitian ini adalah guru honorer Madrasah Ibtidaiyah (MI) di Kota Tangerang. Penelitian ini menggunakan metode penelitian kuantitatif dengan sampel guru honorer MI di Kota Tangerang berjumlah 55 responden. Teknik pengambilan sampel yang digunakan adalah teknik cluster sampling dengan jumlah responden sebanyak 55 orang. Penelitian ini menggunakan dua buah skala yaitu skala psychological well-being dan skala stres yang disusun sendiri oleh peneliti berdasarkan teoriteori stres yang dikemukakan oleh Robbins \& Judge (2013), Gibson, Ivancevich, Donnelly \& Konopaske (2012) dan Newstrom \& Davis (2002). Uji hipotesis dalam penelitian ini menggunakan teknik analisis regresi satu prediktor. Berdasarkan hasil analisis data, bahwa terdapat pengaruh antara stres situasi kerja terhadap psychological well-being pada guru honorer Madrasah Ibtidaiyah (MI) di Kota Tangerang. Pengaruh yang dihasilkan bersifat negatif, artinya jika tingkat stres situasi kerja tinggi, maka tingkat psychological well-being akan rendah.
\end{abstract}

Kata kunci: stres situasi kerja, psychological well-being, guru honorer.

\section{THE INFLUENCE OF STRESS ON THE JOB SITUATION OF PSYCHO- LOGICAL WELL-BEING IN HONORARY TEACHERS GOVERNMENT ELEMENTARY SCHOOL IN THE CITY OF TANGERANG}

\begin{abstract}
This study aims to determine the effect of stress on the job situation of psychological well-being. The population in this study is a honorary teachers in Islamic Elementary School in the City of Tangerang. This study uses a quantitative method with a sample of honorary teachers in Islamic Elementary School in the City of Tangerang amounted to 55 respondents. The sampling technique used was cluster sampling with 55 respondents. This study uses two scale that a scale of psychological well-being and stress scale were arranged by researcher based on the theories of stress advanced by Robbins \& Judges (2013), Gibson, Ivancevich, Donelly \& Konopaske (2012) and Newstrom \& Davis (2002). Test hypothesis in this study using a regression analysis one predictors. Based on the analysis of data, this means that there is influence between stress on the job situation to the psychological well-being on a honorary teacher Islamic Elementary School (MI) in the city of Tangerang. The resulting negative influence, meaning that if the work situation of high stress levels, the levels of psychological well-being will be lower.
\end{abstract}

Keywords : stress on the job situation, psychological well-being, honorary teachers.

\section{PENDAHULUAN}

Kehidupan normal dan sehat adalah idaman semua orang. Setiap manusia berupaya menciptakan kehidupan yang sejahtera baik kondisi fisik, sosial dan psikologisnya. Hal ini dilakukan dalam rangka meningkatkan kualitas hidupnya (Nurhayati, 2010). Seseorang yang mampu melewati dan menghadapi masalah yang terjadi serta mampu berkompetensi mengatur lingkungan sekitar, maka akan mengarah pada kondisi psikologis yang positif dan terbentuklah psychological well-being dalam dirinya.

Pada dasarnya, seseorang yang jiwanya sejahtera tidak sekedar bebas dari tekanan atau masalah mental. Lebih dari itu, ia juga memiliki penilaian positif terhadap dirinya dan mampu bertindak secara otonomi, serta tidak mudah hanyut oleh pengaruh lingkungan. Bila hal ini dikaitkan dengan dunia pekerjaan, maka tingkat psychological well-being seseorang akan berguna dalam komitmen individu, produktivitas kerja individu, target-target dalam pekerjaan, hubungan dengan rekan kerja, serta 
penguasaan lingkungan kerja (Horn dalam Ruth Sumule, 2008).

Ryff (1989, dalam Setiawan \& Budiningsih, 2014) menyatakan bahwa tingkat psychological well-being seseorang berkaitan dengan tingkat pemfungsian positif yang terjadi dalam hidup orang tersebut. Dengan kata lain, psychological wellbeing seseorang akan berkaitan dengan psychological functioning atau kemampuan berfungsi secara psikologis orang tersebut dalam menjalani hidupnya.

Ada enam dimensi yang membangun psychological well-being seseorang diantaranya yaitu penerimaan diri (self-acceptance), hubungan positif dengan orang lain (positive relations with others), kemandirian (autonomy), penguasaan lingkungan (environmental mastery), tujuan hidup (purpose in life), dan pertumbuhan pribadi (personal growth) (Ryff \& Keyes 1995, dalam Sterns, 2007).

Psychological well-being penting untuk diketahui, agar seseorang dapat menjalankan hidupnya dengan bahagia, tenang dan mampu mengatasi berbagai masalah, karena munculnya sebuah masalah dalam kehidupan dapat menimbulkan stres pada seseorang. Stres dapat dialami oleh siapapun, semua tergantung pada stimulus yang dapat memunculkan, hal ini disebut dengan stressor. Lazarus (1966, dalam Hamaideh, 2011) mengemukakan bahwa stressor yang didefinisikan sebagai tuntutan yang berasal dari dalam maupun luar lingkungan, dapat mempengaruhi psychological well-being.

Dunia kerja di bidang pendidikan tidak lepas adanya peran seorang guru yang berupaya mencerdaskan kehidupan bangsa yakni mendidik siswa-siswi agar menjadi individu dengan intelektual yang tinggi. Hendri (2010) menyatakan bahwa pekerjaan guru (mendidik) yang mulia dan seharusnya menyenangkan, sering kali malah menjadi sumber ketegangan lantaran iklim dan kondisi kerja yang terlalu berat dengan beban tugastugas birokrasi, beban sosial-ekonomi dan tantangan kemajuan karir yang terkait erat dengan jaminan hakhak kesejahteraan guru. Kebutuhan guru terkadang kurang mendapat perhatian, padahal tuntutan kerja sebagai guru cukup besar (Mahmud, 1990 dalam Muharomi, 2010). Hal tersebut juga terjadi pada guru honorer.

Kesejahteraan guru honorer Madrasah Ibtidaiyah (MI) di Kota Tangerang ternyata masih jauh dari kata baik. Hidayat Ketua Komisi II DPRD Kota Tangerang, menjelaskan bahwa guru honorer di Kota Tangerang banyak yang belum memiliki upah yang layak. (Kabar-banten, 2012). Hasil wawancara yang telah dilakukan di lapangan dengan beberapa guru di sekolah yang menjadi tempat penelitian ini, bahwa mereka menerima honorarium antara Rp.300.000,00 sampai dengan Rp.1.000.000,00 per bulan. Nominal tersebut sangat minim atau jauh dibawah Upah Minimum Kota Tangerang yaitu sebesar Rp.2.730.000,00 per bulan.

Gaji yang rendah tersebut membuat guru honorer mengalami beberapa hambatan dalam memenuhi kebutuhan fisik, serta mengalami akses untuk meningkatkan kemampuan, memuaskan minat, dan memelihara hubungan, dimana hal-hal tersebut dapat memberikan kepuasan terhadap kebutuhan psikologis mereka. Ryan \& deci (2001, dalam Setiawan \& Budiningsih, 2014) mengatakan bahwa pemenuhan kebutuhan psikologis ini berkaitan dengan psychological well-being seseorang, dimana semakin terpenuhinya kebutuhan psikologis orang tersebut, maka kondisi psychological wellbeing pun akan semakin meningkat. Oleh karena itu, penghasilan sebagai guru honorer dianggap sebagai sesuatu yang sangat penting untuk dapat meningkatkan akses terhadap sumber-sumber penting dalam memperoleh kesenangan dan merealisasikan diri (self-realization).

Selain upah guru honorer yang belum layak, dilansir dari media online yang menyatakan bahwa kondisi gedung MI di Kota Tangerang masih belum memuaskan. Hal ini dapat dibuktikan dengan gedung-gedung yang tidak memadai dan fasilitas di sekolah yang masih kurang (Satelitnews, 2015), padahal disatu sisi guru dituntut untuk memiliki sejumlah kompetensi akademis seperti penguasaan materi pelajaran, mampu mengelola, dan mengevaluasi pembelajaran dengan berbagai metode, serta terampil dalam menggunakan alat peraga dan media pembelajaran (Hendri, 2010). Hal ini membuat guru honorer dituntut untuk dapat mengembangkan kapasistas dirinya yaitu lebih kreatif dan inovatif terutama dalam menciptakan metode pembelajaran untuk siswa-siswi di sekolah demi tercapainya tujuan pendidikan yang sesuai dengan standar pendidikan nasional, agar animo masyarakat lebih meningkat.

Penjelasan di atas menunjukkan bahwa beban kerja serta tuntutan yang selama ini dijalani oleh seorang guru honorer, di satu sisi masih minimnya kondisi kesejahteraan yaitu mengenai pemenuhan hak-hak pada guru honorer. Lahirnya UU No 14 Tahun 2005 tentang guru dan dosen hanya memunculkan sebuah harapan, karena hal tersebut belum terlaksana dengan baik bagi mereka yang berstatus guru honorer MI di Kota 
Tangerang. Berdasarkan penjelasan di atas, maka dapat dilihat bahwa sangat sulit bagi guru honorer MI untuk meningkatkan kesejahteraan hidupnya. Ketidakseimbangan yang muncul dapat membuat guru honorer MI di Kota Tangerang mengalami stres akan situasi kerja yang dapat berdampak pada kondisi psychological well-being.

Jika dilihat dari dimensi-dimensi psychological well-being, bahwa guru honorer yang memiliki tingkat penerimaan diri yang rendah, cenderung tidak puas dengan dirinya sendiri sehingga merasa kecewa dengan apa yang telah terjadi dalam kehidupan pekerjaannya sebagai guru honorer. Guru honorer yang memiliki hubungan positif dengan orang lain yang kurang baik, maka dapat mempengaruhi kinerja sebagai guru honorer yaitu kurang mampu bekerja sama dengan rekan sesama guru dalam mendidik siswa-siswi di sekolah. Kemandirian yang rendah pada guru honorer ditunjukkan dengan ketidakmampuan dalam mempertahankan keyakinannya dalam bekerja seperti memberikan argumentasi saat rapat di sekolah. Penguasaan lingkungan yang rendah pada guru honorer ditunjukkan dengan ketidakmampuan dalam mengatasi masalah-masalah yang dihadapinya sebagai guru honorer seperti mengatasi siswa-siswi yang sulit diatur, selain itu kondisi kerja yang tidak menyenangkan menjadi beban bagi dirinya saat bekerja, seperti batasan-batasan yang dimiliki guru honorer dalam mengembangkan potensi yang dimilikinya. Guru honorer yang tidak memiliki tujuan hidup, tidak dapat mengambil makna dari pengalaman hidupnya sebagai guru honorer di sekolah. Pertumbuhan pribadi yang rendah pada guru honrer ditunjukkan dengan tidak adanya usaha untuk mengembangkan potensi yang dimilikinya sebagai guru, seperti mengajar siswa-siswi dengan apa adanya, tidak menerapkan metode pembelajaran yang menyenangkan, dan tidak ada usaha untuk menyampaikan materi secara maksimal.

Rumusan masalah pada penelitian ini adalah "Apakah terdapat pengaruh stres situasi kerja terhadap psychological well-being pada guru honorer Madrasah Ibtidaiyah (MI) di kota Tangerang?". Penelitian ini diharapkan dapat memberikan manfaat kepada pihak-pihak yang terkait baik secara teoritis dan praktis, diantaranya dapat memberikan informasi bagi pembaca mengenai stres situasi kerja dan psychological well-being pada guru honorer Madrasah Ibtidaiyah (MI), dapat menjadi referensi dalam melakukan pengembangan dan penelitian selanjutnya, dapat memberikan manfaat kepada guru honorer Madrasah Ibtidaiyah (MI) agar mengetahui pentingnya kondisi psychological well-being untuk dapat mengurangi hal-hal yang dapat menyebabkan stres dalam situasi kerja, baik psikologis, fisik dan tingkah laku sehingga kondisi psikologisnya mampu berfungsi dengan baik, dapat memberikan pemahaman baru bagi instansi pendidikan agar memperhatikan aspek-aspek penting tentang kebutuhan pada guru, sehingga guru honorer dapat bekerja secara optimal, memiliki komitmen yang kuat terhadap pekerjaan dan mampu menghadapi tuntutan pekerjaan, dapat memberikan wawasan kepada masyarakat mengenai pentingnya mencapai kondisi psychological well-being yang tinggi agar terhindar dari kondisi stres.

Ryff (1989) mengajukan konsep psychological well-being yang lebih bersifat eudaimonis (Ryan \& Deci, 2001). Terinspirasi oleh konsep eudaimonia dari Aristoteles, Ryff dan koleganya menjelaskan bahwa well-being tidak sebatas sebagai pencapaian kesenangan namun sebagai " the striving for perfection that represents the realization of one's true potential" (Ryff, 1995 dalam Ryan \& Deci, 2001). Ryff \& Keyes (1995 dalam Ryan \& Deci 2001) menyusun konsep psychological well-being dengan model multidimensional, yang didapatkan dari diskusi teoritis tentang optimal aging, atau kondisi usia lanjut dimana individu masih dapat berfungsi dengan optimal, keberfungsian positif, dan perkembangan normal manusia.

Ryff \& Keyes (1995) menjelaskan bahwa psychological well-being merupakan kemampuan individu dalam menerima keadaan dirinya, membentuk hubungan yang hangat dengan orang lain, mampu mengendalikan dirinya dan mandiri terhadap tekanan sosial, serta mampu untuk merealisasikan potensi yang dimilikinya sehingga memiliki arti dalam hidupnya.

Ada enam dimensi yang membangun psychological well-being seseorang. Dimensi yang pertama adalah penerimaan diri (self-acceptance), yaitu kepemilikan sikap yang positif terhadap diri. Kedua adalah hubungan positif dengan orang lain (positive relations with others), yaitu kemampuan seseorang untuk membina hubungan yang baik dengan orang lain. Ketiga adalah kemandirian (autonomy), yaitu kemampuan seseorang untuk mengambil keputusan bagi dirinya sendiri berdasarkan standar pribadi dan tidak bergantung pada pandangan orang lain. Keempat adalah penguasaan lingkungan (environmental mastery), yaitu kemampuan seseorang untuk memilih atau membentuk lingkungan yang sesuai dengan keadaan dirinya. Kelima adalah 
tujuan hidup (purpose in life), yaitu kepercayaan yang menimbulkan perasaan bahwa hidup itu berarti dan memiliki tujuan, dimensi yang terakhir adalah untuk pertumbuhan pribadi (personal growth), yaitu kemampuan untuk mengembangkan potensi diri (Ryff \& Keyes 1995, dalam Sterns, 2007).

Berdasarkan beberapa hasil penelitian sebelumnya, terdapat faktor-faktor yang mempengaruhi psychological well-being seseorang, diantaranya adalah jenis kelamin (Ryff, 1989), usia (Ryff dalam Ryan \& Deci, 2001), kepribadian (Schumutte \& Ryff dalam Ryan \& Deci, 2001), kecerdasan emosi (Shulman \& Hemenover dalam Extremera, Aranda, Galan \& Salguero, 2011), budaya (Ryff, 1989), status sosial ekonomi (Ryff, dalam Ryan \& Deci, 2001), stres (Atkinson, 2000).

Stres adalah kondisi dinamis individu dalam menghadapi peluang, kendala, tuntutan yang terkait dengan apa yang sangat diinginkannya dan hasilnya dipersepsikan sebagai sesuatu yang tidak pasti tetapi merupakan sebuah hal yang penting (Robbins \& Judge, 2013). Menurut Gibson, Ivancevich, Donnelly \& Konopaske (2012) stres adalah suatu pengalaman yang umum terjadi pada setiap orang. Stres sebagai respon adaptif yang dialami oleh seseorang yang disebabkan dari berbagai situasi, tindakan serta tuntutan yang ada. Pendapat lain yang dikemukakan oleh Newstrom \& Davis (2002, dalam Hasan \& Akter, 2014) bahwa stres sebagai istilah umum yang dipakai untuk menggambarkan orang yang mengalami tekanan dalam hidupnya dan kondisi stres banyak terjadi hampir di setiap bidang kegiatan dalam dunia kerja.

Di dalam dunia kerja, terdapat stres kerja yaitu ketegangan yang sering dialami oleh karyawan yang dapat mengganggu situasi kerja serta konsentrasi dalam menyelesaikan tugas (Rustiana \& Cahyati, 2012). Newstrom \& Davis (2002, dalam Hasan \& Akter, 2014) mengemukakan typical negative symtoms of unmanaged stress yang terdiri dari tiga aspek yaitu (a) physiological; ulcers, digestive problem, headaches, high blood pressure, sleep disruption, (b) psychological; emotional instability, moodiness, nervousness and tension, chronic worry, depretion, burnout, (c) behavioral; excessive smooking, abuse of alcohol or drugs, aggression, safety problem, performance problem.

Berdasarkan penjelasan di atas dapat disimpulkan bahwa stres situasi kerja merupakan ketegangan yang timbul sebagai reaksi dari stresor yang dirasakan oleh individu dalam menghadapi tuntutan dan kendala pada situasi kerja yang melebihi beban kemampuannya, yang ditandai dengan adanya respon fisik, psikologis dan tingkah laku. Faktor-faktor yang mempengaruhi stres pada individu (Kozier 1998, dalam Azmi, 2014) antara lain (1) sifat dari stresor yang dihadapi, yaitu faktor yang dapat mempengaruhi respon tubuh terhadap stresor; (2) persepsi terhadap stresor, yaitu cara yang dihadapinya akan mempengaruhi tingkat stres; (3) jumlah stresor, dimana individu banyak menerima stresor dalam waktu bersamaan. Jika individu tidak siap akan menimbulkan perilaku yang tidak baik; (4) lama stresor, merupakan lamanya individu terpapar oleh stresor. Jika lamanya stresor melebihi batas pertahanan dan kekuatan koping, individu akan merasa lelah sehingga sulit beradaptasi dan mengatasi stres pada situasi yang serupa; (5) pengalaman masa lalu terhadap stres, merupakan faktor yang dapat membantu individu dalam beradaptasi dan mengatasi stres pada situasi yang sama; dan (6) usia, merupakan salah satu faktor yang dapat mempengaruhi bagaimana individu mengatasi stresor dengan baik.

\section{METODE PENELITIAN}

Pendekatan yang dilakukan dalam penelitian ini adalah pendekatan sacara kuantitatif. Populasi yang digunakan pada penelitian ini adalah guru honorer Madrasah Ibtidaiyah (MI) di Kota Tangerang. Teknik pengambilan sampel pada penelitian ini adalah teknik probability sampling karena memberikan peluang yang sama kepada setiap anggota populasi untuk terpilih menjadi anggota sampel.

Jenis teknik sampling yang digunakan adalah cluster sampling. Menurut Rangkuti (2013), cluster sampling merupakan teknik sampling yang digunakan jika sumber data sangat luas, misalnya penduduk, suatu negara, provinsi, atau kabupaten.

Dalam menentukan jumlah sampel, menggunakan tahap pertama pada teknik cluster sampling yaitu menentukan sampel area atau daerah. Terdapat 13 kecamatan di Kota Tangerang yang memiliki kesempatan yang sama untuk menjadi sampel, sehingga dilakukan pengocokan dari 13 kecamatan tersebut untuk menentukan satu kecamatan yang akan dijadikan sebagai sampel penelitian ini. Dari hasil pengocokan, terpilih satu kecamatan di Kota Tangerang yaitu kecamatan Jatiuwung. Pada kecamatan ini terdapat 7 sekolah Madrasah Ibtidaiyah (MI) yang masing-masing terdapat guru honorer yang akan dijadikan sebagai sampel penelitian ini.

Teknik pengumpulan data yang digunakan dalam penelitian ini adalah dengan menggunakan 
skala psikologi, dimana alat ukur ini mengukur atribut non-kognitif berupa pernyataan, dimana respon subjek tidak diklasifikasikan sebagai jawaban yang benar atau salah (Azwar, 2012).

Penelitian ini menggunakan dua buah skala psikologi yang mengukur kedua variabel yang digunakan, yaitu skala yang dikonstruk oleh peneliti berdasarkan dari teori Robbins \& Judge (2013), Gibson, Ivancevich, Donnelly \& Konopaske (2012) dan Newstrom \& Davis (2002, dalam Hasan \& Akter, 2014) untuk mengukur variabel stres situasi kerja, dan adaptasi Ryff's Scale (1995) untuk mengukur variabel psychological well-being.

Skala pengukuran yang digunakan pada instrumen yang dikonstruk untuk variabel stres situasi kerja menggunakan skala Likert yang terdiri dari 5 pilihan jawaban yaitu Tidak Pernah, Jarang, Kadang-kadang, Sering, Selalu. Sedangkan skala pengukuran yang digunakan untuk mengukur psychological well-being berdasarkan instrumen aslinya, yaitu terdiri dari 6 pilihan jawaban yaitu Sangat Tidak Setuju, Cukup Tidak Setuju, Sedikit Tidak Setuju, Sedikit Setuju, Cukup Setuju, Sangat Setuju.

Uji statistik yang digunakan adalah analisis regresi satu prediktor. Penganalisisan data dilakukan secara pemodelan Rasch dengan bantuan aplikasi winstep versi 3.73 dan pengujian hipotesis menggunakan aplikasi SPSS versi 16.0.

\section{HASIL DAN PEMBAHASAN}

Hasil uji normalitas yang dilakukan terhadap dua variabel, menunjukkan hasil bahwa variabel stres situasi kerja dan variabel psychological well-being berdistribusi normal. Hal ini terlihat dari nilai $\mathrm{p}>\mathrm{a}$ $(0,05)$.

Hasil uji linieritas menunjukkan nilai $p(0,008)<$ $a(0,05)$, artinya variabel stres situasi kerja dan variabel psychological well-being memiliki huungan yang linier. Hubungan yang linier antara kedua variabel juga dapat dilihat pada grafik Scatter Plot. Berikut grafik Scatter Plot kedua variabel:

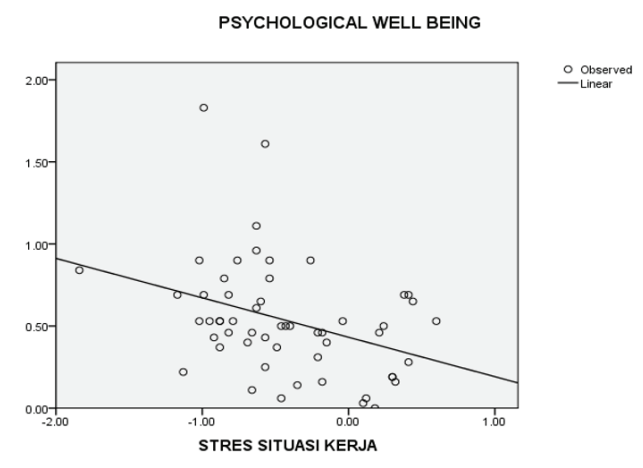

Gambar 1 Grafik Scatter Plot kedua variabel
Korelasi antara variabel stres situasi kerja dan psychological well-being memiliki koefisien korelasi $-0,356$ dengan nilai $p=0,004$. Nilai $p$ lebih kecil daripada $\alpha=0,05$, artinya terdapat korelasi yang signifikan antara variabel stres situasi kerja dengan psychological well-being.

Setelah itu, dilakukan uji regresi untuk mengetahui adakah pengaruh antara stres situasi kerja terhadap psychological well-being. Hasilnya diketahui bahwa konstanta variabel psychological well-being sebesar 0,432 sedangkan koefisien regresi variabel stres situasi kerja $-0,240$. Berdasarkan data di atas dapat ditentukan persamaan regresinya sebagai berikut:

$$
\begin{aligned}
& Y=a+B x \\
& Y=0,432-0,240 X
\end{aligned}
$$

Dari hasil tersebut dapat diketahui bahwa terdapat pengaruh antara stres situasi kerja terhadap psychological well-being.

Selanjutnya, dilakukan uji signifikansi keseluruhan untuk menguji hipotesis yang telah dibuat. Berdasarkan hasil analisis regresi dapat diketahui $\mathrm{F}$ hitung sebesar 7,708 dengan nilai $\mathrm{p}=$ 0,008 . Jika nilai $p$ dibandingkan dengan $\alpha=0,05$ maka dapat disimpulkan $\mathrm{p}<\alpha$ yang artinya hipotesis nol (Ho) dalam penelitian ini ditolak dan hipotesis alternatif (Ha) diterima. Jika dibandingkan dengan menggunakan $\mathrm{F}$ hitung dan $\mathrm{F}$ tabel $(1 ; 53)$, hasil $\mathrm{F}$ tabel sebesar 4,03 artinya $\mathrm{F}$ hitung > F tabel. Kesimpulannya adalah Ho ditolak, dengan kata lain terdapat pengaruh antara stres situasi kerja terhadap psychological wellbeing pada guru honorer Madrasah Ibtidaiyah (MI) di Kota Tangerang.

Hasil penghitungan korelasi ganda $(\mathrm{R})$ yang diperoleh dari hasil penghitungan adalah -0,356 dan Adjusted $R$ square sebesar 0,110. Artinya variabel stres situasi kerja mempengaruhi variabel psychological well-being sebanyak $11 \%$ dan sisanya dipengaruhi oleh faktor lain diluar psychological well-being.

Keterkaitan antara stres situasi kerja terhadap psychological well-being telah dibuktikan melalui penelitian skripsi yang dilakukan oleh Diah Mardiah (2009). Dalam penelitiannya, Mardiah (2009) mencari bagaimana hubungan antara variabel stres dan psychological well-being pada istri karyawan perkebunan kelapa sawit. Hasil dari penelitian tersebut menyatakan bahwa terdapat hubungan yang signifikan dan bersifat negatif. Penelitian ini mengembangkan dari penelitian Mardiah (2009) yang hanya melakukan uji korelasi. Selain itu, hasil penelitian yang dilakukan Jasmani binti Mohd Yunus dan Abdul Jumaat bin Mahajar (2011) mengatakan bahwa stres dan psychological 
well-being pada pemerintahan di Malaysia memiliki hubungan dan pengaruh yang signifikan.

Berdasarkan hasil penelitian yang mengatakan bahwa terdapat pengaruh yang signifikan antara stres situasi kerja terhadap psychological well-being pada guru honorer MI di Kota Tangerang, maka implikasi penelitian ini yaitu perlu adanya usaha dan upaya dari pemerintah dan dari pihak kepala sekolah agar memperhatikan kondisi kesejahteraan psikologis guru honorer yang akan berdampak pada kinerjanya, mengadakan kegiatan-kegiatan serta melakukan evaluasi diri pada guru honorer. Hal ini dilakukan agar guru honorer terhindar dari kondisi stres yang dapat mengganggu kondisi psychological well-being pada dirinya.

Memiliki psychological well-being yang tinggi menjadi hal yang penting. Ryff \& Keyes (1995) menjelaskan bahwa psychological well-being merupakan kemampuan individu dalam menerima keadaan dirinya, membentuk hubungan yang hangat dengan orang lain, mampu mengendalikan dirinya dan mandiri terhadap tekanan sosial, serta mampu untuk merealisasikan potensi yang dimilikinya sehingga memiliki arti dalam hidupnya.

Guru honorer yang memiliki psychological wellbeing tinggi akan memiliki komitmen individu dan produktivitas kerja yang baik, mampu mengajar siswasiswi dengan profesional, menyelesaikan pekerjaan tepat waktu, dan dapat menciptakan hubungan yang harmonis dengan rekan-rekan seprofesi. Apabila individu memiliki kondisi psychological well-being yang baik, maka secara psikologis ia mampu berfungsi dengan baik.

\section{PENUTUP}

\section{Kesimpulan}

Berdasarkan hasil penelitian, analisis data dan pembahasan yang diperoleh dari pengujian secara statistik dapat disimpulkan bahwa terdapat pengaruh yang signifikan stres situasi kerja terhadap psychological well-being pada guru honorer Madrasah Ibtidaiyah (MI) di Kota Tangerang. Pada penelitian ini, pengaruh yang dihasilkan bersifat negatif, yang artinya semakin tinggi tingkat stres situasi kerja guru honorer, maka akan semakin rendah tingkat psychological well-being guru honorer. Dengan kata lain, hasil pengujian statistik dalam penelitian ini adalah Ho ditolak dan Ha diterima. Pengaruh stres situasi kerja terhadap psychological well-being sebesar 11\% dan $89 \%$ lainnya dipengaruhi oleh faktor lain yang tidak diteliti dalam penelitian ini.

\section{Saran}

\section{Untuk Guru Honorer}

Banyak hal-hal yang dapat dilakukan agar guru honorer mencapai kesejahteraan psikologisnya, diantaranya mengadakan kegiatan-kegiatan yang menyenangkan baik di lingkungan kerja maupun di luar lingkungan kerja. Selain itu, diharapkan juga dapat menerima kondisi diri sendiri tanpa harus membandingkan diri dengan orang lain dan setiap hal yang dilalui dalam kehidupan dapat diambil maknanya yang bisa bermanfaat bagi dirinya sendiri.

\section{Pemerintah}

Diharapkan pemerintah memperhatikan kembali kondisi para guru honorer, misalnya dalam hal pemenuhan hak-hak sebagai guru honorer yang harus dipenuhi. Saat ini, penghasilan yang diperoleh guru honorer tidak sesuai dengan beban kerja yang dijalani. Selain itu, sarana dan prasarana yang dimiliki setiap MI masih kurang memadai.

\section{Peneliti Selanjutnya}

Diharapkan peneliti selanjutnya dapat melakukan penelitian menggunakan sampel guru Pegawai Negeri Sipil (PNS) agar dapat dilihat tingkat psychological well-being pada guru PNS sehingga dapat dilihat perbedaannya dengan guru honorer.

\section{DAFTAR PUSTAKA}

Anonim. (2015, Mei 4). Madrasah minta perhatian pemerintah. Satelitnews. (Diakses dari http:// www.satelitnews.co.id/madrasah-minta-perhatian-pemerintah)

Atkinson. (2000). Pengantar psikologi edisi kesebelas jilid 2. Jakarta: Interaksara.

Azmi, H. (2014). Gambaran tingkat stres dilihat dari aspek fisik dan emosional pada pengajar anak autis. Skripsi. Fakultas Psikologi Universitas Islam Negeri Syarif Hidayatullah Jakarta.

Azwar, S. (2012). Penyusunan skala psikologi. Yogyakarta: Pustaka Pelajar.

Extremera, N., Aranda, D. R., Galan, P., \& Salguero, J. M. (2011). Emotional intelligence and it's relation with hedonic and eudemonic well-being: A prospective study. Personalit and Individual Difference, $51,11,16$.

Gaji Guru Honorer Distandardisasi. (2012). (Diunduh tanggal 2 Maret 2016 dari http:/ / www.kabarbanten.com/news/detail/8658)

Gibson, J. L., Ivancevich, J. M. Donnelly, J.H., \& Konopaske, R. (2012). Organizations behavior, structure, processes: Fourteenth Edition. New York: McGraw-Hill. 
Hamaideh,S. H. (2011). Stressors and reactions to stressor among university students. International Journal of Psychiarty.

Hasan, M.R., \& Akter, T. (2014). Stress stimulation for the employees of service industry in Dhaka \& It's Vicinity. Developing Country Studies. Vol.4, No.12, 133-140.

Hendri, E. (2010). Guru berkualitas: Profesional dan cerdas emosi. Jurnal Saung Guru, Vol. 1, No. 2.

Muharomi, E. (2010). Stres kerja ditinjau dari persepsi terhadap beban kerja pada guru yang mengajar mata pelajaran ujian nasional tingkat Sekolah Menengah Atas di Kota Yogyakarta. Skripsi. Fakultas Ilmu Sosial dan Humaniora Universitas Islam Negeri Sunan Kalijaga Yogyakarta.

Nurhayati, H. (2010). Pengaruh big five personality terhadap psychological well being remaja di Sekolah Menengah Kejuruan Negeri Madiun. Skripsi Fakultas Psikologi Universitas Islam Negeri Maulana Malik Ibrahim Malang.

Rangkuti, A. A. (2013). Statistik inferensial untuk penelitian psikologi dan pendidikan. Jakarta: FIP Press.

Robbins S. P., \& Judge, T. A. (2013). Organizational behavior. New Jersey: Pearson Prentice Hall.
Rustiana, E.R., \& Cahyati, W.H. (2012). “Stres Kerja dengan Pemilihan Strategi Coping". Jurnal Kesehatan Masyarakat. Vol.7, No.2, 149-155.

Ryan, M. R., \& Deci, E. L. (2001). On happiness and human potentials: A review of research on hedonic and eudaimonic well being. Annual Reviews Psychol, No. 52, 141-166.

Ryff, C. D. (1989). "Happiness is everything, or is it? exploration on the meaning of psychological well being". Journal of Personality and Social Pschology, Vol. 57, No. 6, 1069-1081.

Ryff, C.D \& Keyes, C.L.M. (1995). "The structure of psychological well being revisited". Journal of Pesonality and Social Psychology. 69, (4), 719-727.

Setiawan, H., \& Budiningsih, T. E. (2014). “Psychological well being pada guru honorer sekolah dasar kecamatan Wonotunggal Kabupaten Batang". Educational Psychology Journal, Vol. 3, No. 1, 8-14.

Sterns, S. (2007). Factor that impact the health and psychological well being of older adults shortly following institutionalization. Case Western Reserve University: Departement of Sociology.

Sumule, R.(2008). Psychological well-being pada guru yang bekerja di yayasan PESAT Nabire. Gunadarma University Journal. 